\title{
COMPARATIVE RESPONSE ON THE ACCUMULATION OF INORGANIC PHOSPHATE IN LEAF OF BASELA ALBATO LOW AND HIGH TEMPERATURE
}

\author{
Md Shahidul Haque ${ }^{1 *}$, Md Monirul Islam ${ }^{1}$, Tanzima Yeasmin ${ }^{2}$ \\ ${ }^{1}$ Department of Biochemistry and Molecular Biology, Laboratory of Protein and Enzyme Research, \\ University of Rajshahi, Rajshahi-6205, Bangladesh \\ 2 Institute of Biological Sciences, University of Rajshahi, Rajshahi-6205, Bangladesh
}

\begin{abstract}
Context: Basella alba is a green vegetable and grows in both winter and summer; however the temperature sensitivity on metabolic regulation in this species is not clarified.

Objectives: To find the role of low and high temperature induced regulation of metabolic functions particularly alteration and accumulation of inorganic phosphate in leaf.

Materials and Methods: Plants grown in pot were exposed to cold $\left(8^{\circ} \mathrm{C}\right)$ for $24 \mathrm{~h}, 48 \mathrm{~h}$ and $72 \mathrm{~h}$ periods and the respective controls were kept in ambient room temperature for the above mentioned time. For high temperature induced plants, they were exposed to $45^{\circ} \mathrm{C}$ with full aeration along with sufficient water. Control pot was used similarly in room temperature; however, the temperature was maintained $30^{\circ} \mathrm{C}$ by using air cooling system (AC).

Results: Low temperature causes the higher inorganic phosphate level in leaf and was increased by $33.6 \%, 34.7 \%$ and $62.8 \%$ respectively when compared to the respective controls. Therefore, it is assumed that short term exposure has mild effect on phosphate accumulation in leaf; conversely as the time extended, the synthesis assumed to be higher and increased time dependently. Similarly, the inorganic phosphate concentrations were increased by $27.8 \%, 37.5 \%$ and $74.9 \%$ respectively whenever the plants were exposed to high temperature $\left(45^{\circ} \mathrm{C}\right)$. Taken together, a faster increase in accumulation of phosphate in leaf was mediated by high temperature for prolonged exposure.

Conclusion: The plants exposed to both abiotic stresses cause the release of inorganic phosphate which may participate in the survival of the species in the adverse environment.
\end{abstract}

Key words: Temperature stress, Metabolic effects, Basella alba, Adaptive response.

\section{Introduction}

Environmental stress might disrupt cellular structures and impair key physiological functions of plants (Larcher 2003). Drought, salinity and low temperature stresses impose an osmotic stress that result in turgor loss. Membranes may become disorganized, proteins may undergo loss of activity or be denatured and often excess levels of reactive oxygen species (ROS) are produced leading to oxidative damage. The previous investigations reveal that chilling induced injury is associated with the formation of ROS, such as superoxide $\left(\mathrm{O}_{2}^{-}\right)$, hydrogen peroxide $\left(\mathrm{H}_{2} \mathrm{O}_{2}\right)$, hydroxyl radical $\left(\mathrm{OH}^{-}\right)$and singlet oxygen $\left({ }^{1} \mathrm{O}_{2}\right)$ (Basra 2001, Lee and Lee 2000). To prevent the oxidative damage caused by such abiotic stress, plants generate different mechanism by which they can survive in such critical environment. Antioxidative enzymes like superoxide dismutase (SOD), catalase (CAT) and peroxidase (PRX) are the most important components in the scavenging system of ROS. Several lines of evidences reveal that antioxidative enzymes and anti oxidant molecules can neutralize ROS (Oidaira et al. 2000, Lee and Lee 2000). These antioxidant molecules might be involved to regulate the metabolic sequences, for example, degradation of high energy rich

\footnotetext{
*Corresponding author E-mail: haque_drshahidul@yahoo.co.in
} 
molecules like ATP, GTP to produce inorganic phosphate and the enzymes involved in this process might be influenced. Phosphorus is an essential nutrient for plants and an important component in cell metabolism. It has a vital functional role in energy transfer, and acts as modulator of enzyme activity and gene transcription; hence its assimilation, storage and metabolism are of major importance to plant growth and development. Hydrolytic breakdown of phosphate esters is brought about by phosphatases, which is a critical process in energy metabolism, metabolic regulation and a wide range of signal transduction pathways in plants. It is assumed that the oxidative stress caused by low and high temperature might be involved in the hydrolytic degradation of phosphates esters. The released inorganic phosphate may serve as the essential molecule in such adverse environmental situations like cold and draught.

Basella alba is a very soft leafy vegetable available in Bangladesh and grows both in summer and winter. The diverse clinical importance of this plant was demonstrated by recent investigations (Roshan et al. 2012, Premalatha et al. 2005). Therefore, it is assumed that variation of temperature may affect both metabolic activities as well as its biological importance. The aim of this study is to examine the interrelationship between important nutrients of plant metabolism, such as phosphorus and the physiological mechanisms such as cold acclimation or high temperature stress in $B$ alba. The current investigation has also been undertaken to find the role of cold acclimation and high temperature treatment on the regulation of metabolic functions, particularly, alteration and accumulation of leaf inorganic phosphate of Basella alba and may assist in the clarification of such stress-induced mechanisms.

\section{Materials and Methods}

Plant materials and low temperature treatment: For this experiment, two plastic pots were used; each pot size was $70 \mathrm{~cm}$ in diameter and $24 \mathrm{~cm}$ in height. An adequate amount of soil was taken in each plastic pot and the plastic pots were seeded with Basella alba. For the germination of seeds, the following points were carried out: i) the strong seeds were selected; the seeds were added to normal water and the floating seeds were discarded; ii) the seeds were kept in normal water with temperature below $37^{\circ} \mathrm{C}$ for overnight; iii) the seeds which were swollen by water absorption, were expected to be effective for germination; iv) the seeds were seeded in the pots prepared with soil and the efficiency of seed germination was $65 \%-75 \%$. After 30 days of germination, the two different pots were described as control and low temperature induced plants. Control pot was used for $24 \mathrm{~h}, 48 \mathrm{~h}$ and $72 \mathrm{~h}$ treatments in the room temperature without cold acclimation. The second pot was used for $24 \mathrm{~h}, 48 \mathrm{~h}$ and $72 \mathrm{~h}$ duration in the temperature controlled cooling chamber and given cold exposure $\left(8^{\circ} \mathrm{C}\right)$ with full aeration. After the treatments, leaves were collected consecutively from each pot for $24 \mathrm{~h}, 48 \mathrm{~h}$ and $72 \mathrm{~h}$ duration and kept in $-80^{\circ} \mathrm{C}$.

Plant materials and high temperature treatment: In separate experiments, another two plastic pots were prepared with soil and seeded similarly with Basella alba. After 30 days of germination, the two different pots were described as control and high temperature induced plants. Control pot was used for $24 \mathrm{~h}, 48 \mathrm{~h}$ and $72 \mathrm{~h}$ treatments in room temperature; however, the temperature was maintained $30^{\circ} \mathrm{C}$ by using air cooling system (AC) already fixed in the room. The second pot was used similarly for $24 \mathrm{~h}, 48 \mathrm{~h}$ and $72 \mathrm{~h}$ duration in the plastic chamber and was exposed to $45^{\circ} \mathrm{C}$ with full aeration along with sufficient water. To maintain this temperature, electric bulbs $(2 \times 200 \mathrm{~W})$ were connected to the chamber. After the treatments, the leaves were collected consecutively from each pot for $24 \mathrm{~h}, 48 \mathrm{~h}$ and $72 \mathrm{~h}$ duration and kept in $-80^{\circ} \mathrm{C}$.

Assay of inorganic phosphate (Pi): The leaves of the different treatments $(24 \mathrm{~h}, 48 \mathrm{~h}$ and $72 \mathrm{~h})$ and their respective controls were homogenized with water in a mortar kept on ice. Approximately, $3 \sim 4 \mathrm{~g}$ of cold exposed and their respective control leaves were used for homogenization while approximately $2 \sim 3 \mathrm{~g}$ of high temperature induced leaves and their respective controls were similarly used. The homogenates were centrifuged at $8000 \mathrm{rpm}$ for 10 minutes and the supernatants were used as crude extract for assay of inorganic phosphate (Pi) as described by Ramnik (1999). $200 \mu$ l tissue extract was diluted to $5 \mathrm{ml}$ with water 
and was mixed vigorously with $5 \mathrm{ml}$ of 5\% TCA (Trichloroacetic acid) and centrifuged at $6000 \mathrm{rpm}$ for $10 \mathrm{~min}$. $5 \mathrm{ml}$ supernatant was transferred to another tube and kept on ice. $1 \mathrm{ml}$ molybdate reagent $(10 \mathrm{~g}$ of ammonium molybdate in $100 \mathrm{ml}$ water was taken and $100 \mathrm{ml}$ of $5 \mathrm{~N} \mathrm{H}_{2} \mathrm{SO}_{4}$ was added to prepare $200 \mathrm{ml}$ solution) was added and mixed. The solution was mixed with $0.4 \mathrm{ml}$ of aminonaptholsulphonic acid reagent. An amount of $3.6 \mathrm{ml}$ water was added and after mixing, the tube was kept standing for 10 min for the complete development of color. For blank, $5 \mathrm{ml}$ of $5 \%$ TCA and $5 \mathrm{ml}$ water were mixed only. Absorbance was taken at $690 \mathrm{~nm}$ against the blank. The Pi contents in leaf extract were calculated using standard $\mathrm{KH}_{2} \mathrm{PO}_{4}$ solution.

Statistical analysis: Results of the experiments were expressed as mean and standard error of different groups. The differences between the mean values were evaluated by ANOVA followed by paired $t$-test using SPSS software.

\section{Results}

Effects of low temperature on Pi content in leaf of Basella alba:

To properly identify the physiological responses to environmental stress such as low temperature, plants were exposed to $8^{\circ} \mathrm{C}$ in a temperature controlled cooling chamber for $24 \mathrm{~h}$. As shown in Fig. $1 \mathrm{~A}$, the average inorganic phosphate content in leaf in response to low temperature for $24 \mathrm{~h}$ period was $105.32 \pm 0.88 \mathrm{mg} / 100$ $\mathrm{g}$ of leaf whereas for the control leaf kept in ambient temperature, the amount of Pi was $78.83 \pm 3.92 \mathrm{mg}$. A significant $(33.6 \%, P<0.05)$ increased Pi was observed after $24 \mathrm{~h}$ when compared with control plant (Fig. 3$)$. The results appeared to indicate that the Pi contents were affected by cold acclimation. Therefore, it is reasonable that an adaptive response by the species was created and the accumulation of Pi was observed to serve as the factor responsible for the adverse environmental condition.
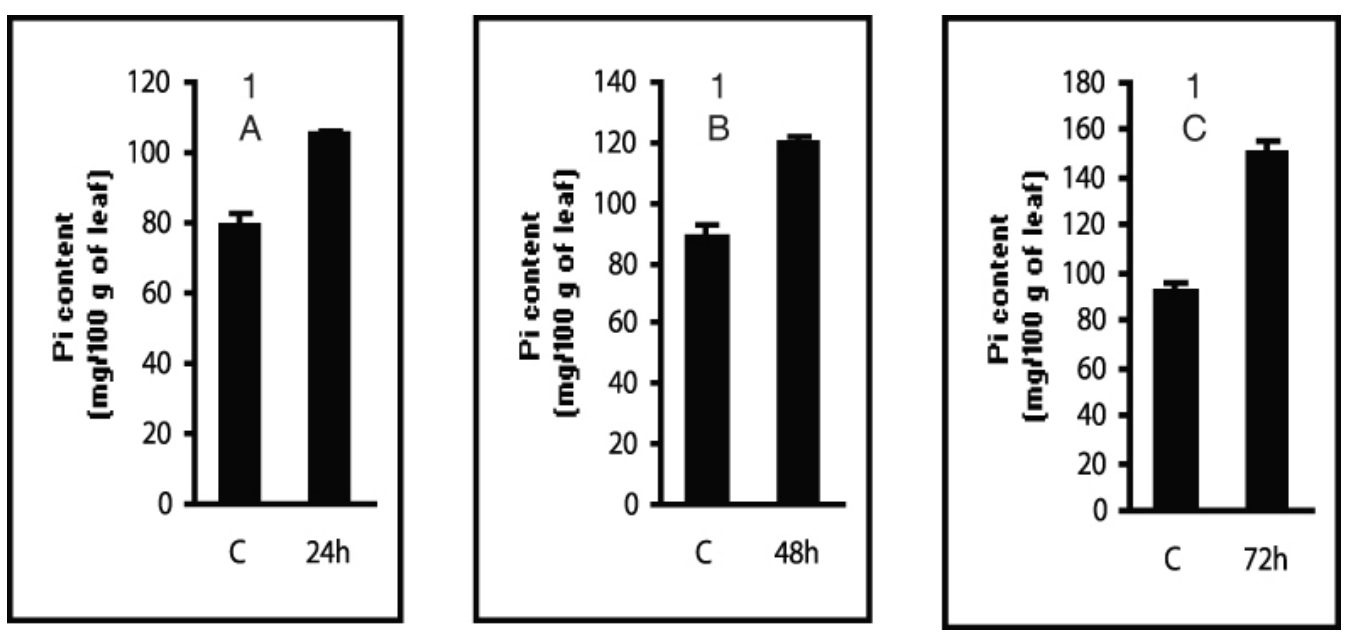

Fig. 1. Low temperature induced regulation of Pi accumulation in leaves of Basella alba. The plants exposed to cold (8 $\left.{ }^{\circ} \mathrm{C}\right)$ for $24 \mathrm{~h}(1 \mathrm{~A}), 48 \mathrm{~h}(1 \mathrm{~B})$ and $72 \mathrm{~h}(1 \mathrm{C})$ in cold chamber, however, the respective controls were used without any cold acclimation. The leaves of plants of different treatments and their respective controls were used for determination of Pi. The results are means of \pm SE for 3 values in each group. 
Leaves of Basella alba were exposed to low temperature for $48 \mathrm{~h}$ and the amount of Pi was $119.99 \pm 1.48 \mathrm{mg}$ while for the respective control plant, the Pi content was $89.02 \pm 3.91 \mathrm{mg} / 100 \mathrm{~g}$ of leaf. The results indicated that $34.78 \%(P<0.01)$ increased $\mathrm{Pi}$ had been found after $48 \mathrm{~h}$ in response to cold compared to the control plant (Fig. 1B and Fig. 3). The increased accumulation of Pi in leaf in response to cold environment might be involved in the regulation of metabolic functions of this species of plant. The alteration of Pi concentration in leaf is an index for characterization of the sensitivity to the environmental temperature.

To find the optimum effect of cold acclimation on Pi content in leaf, the extended time was $72 \mathrm{~h}$. As shown in Fig. 1C, the low temperature induced leaf had Pi content $150.56 \pm 4.20 \mathrm{mg}$ while for the respective control leaf, the average Pi content was $92.45 \pm 3.41 \mathrm{mg} / 100 \mathrm{~g}$ of leaf. The results showed that the Pi content in leaf had been enhanced significantly $(P<0.001)$ by $62.85 \%$ when they were exposed to cold for $72 \mathrm{~h}$, compared to the control (Fig. 3). The results appeared to indicate that the Pi contents were affected by cold acclimation and was assumed that the prolonged cold exposure had higher stimulatory effects on Pi release in leaf of the plant than $24 \mathrm{~h}$ and $48 \mathrm{~h}$ periods. The results suggest that the increased Pi induced by low temperature might be caused by such abiotic stress and could be considered as the survival factor for this species of plant in critical environment.

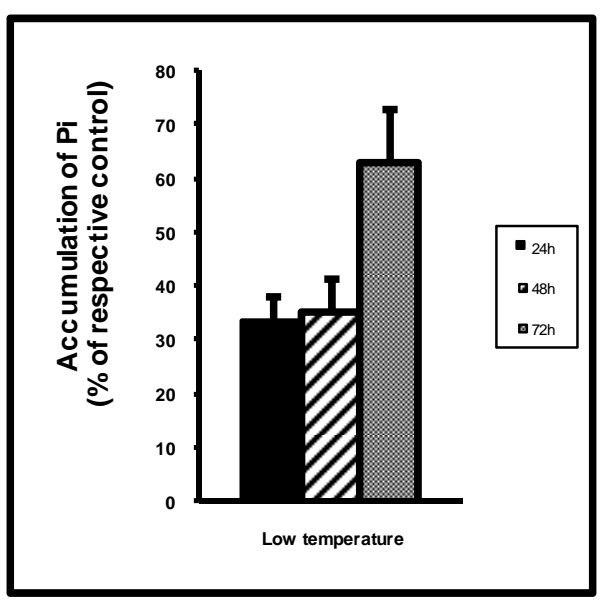

Fig. 3. Accumulation of Pi in leaves of Basella alba during cold acclimation. The plants exposed to cold $\left(8^{\circ} \mathrm{C}\right)$ for $24 \mathrm{~h}, 48 \mathrm{~h}$ and $72 \mathrm{~h}$ in cold chamber, however, the respective controls were used without any cold acclimation. After the treatments, the leaves of the plants and their respective controls were used for determination of inorganic phosphate. The results are expressed as percentage of the respective controls

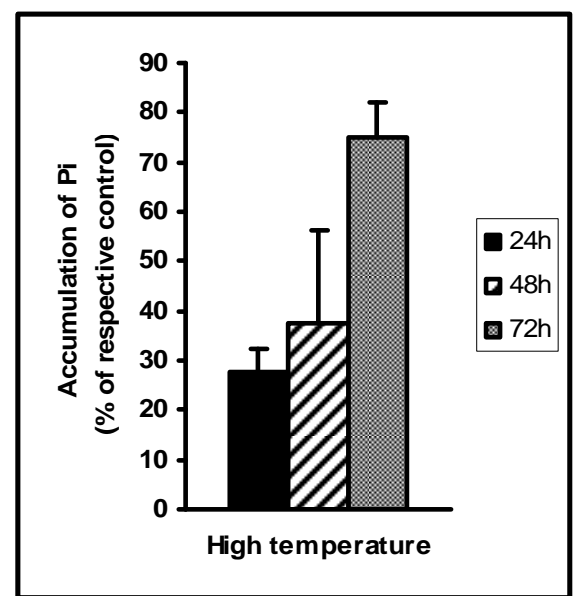

Fig. 4. Accumulation of $\mathrm{Pi}$ in leaves of Basella alba during high temperature acclimation. The plants were exposed to $45{ }^{\circ} \mathrm{C}$ for $24 \mathrm{~h}, 48 \mathrm{~h}$ and $72 \mathrm{~h}$ periods in the high temperature producing chamber. The respective controls were kept in the room where the temperature remains 30 ${ }^{\circ} \mathrm{C}$ and was maintained by air cooling system. After the treatments, the leaves of the plants and their respective controls were used for determination of inorganic phosphate. The results are expressed as percentage of the respective controls.

Effect of high temperature on Pi content in leaf of Basella alba:

To examine the role of high temperature on the regulation of inorganic phosphate accumulation in leaf of Basella alba, plants in the pot were exposed to $45^{\circ} \mathrm{C}$ in plastic chamber equipped in the laboratory for $24 \mathrm{~h}$ period and the respective control was kept in $30^{\circ} \mathrm{C}$. The amount of $\mathrm{Pi}$ in response to high temperature was $68.36 \pm 0.81 \mathrm{mg} / 100 \mathrm{~g}$ of leaf, whereas for control leaves, the Pi content was $53.46 \pm 2.37 \mathrm{mg}$. The results 
demonstrated that Pi contents had been significantly enhanced and stimulated $(27.87 \%, P<0.05)$ by high temperature compared to the respective control. However, the accumulation of Pi was appeared to be lower than the low temperature shown in Fig. 2A, Fig. 1A and Fig. 4.

As shown in Fig. 2B, the amount of $\mathrm{Pi}$ in leaves of plant was recorded to determine the effect of high temperature on inorganic phosphate accumulation. After $48 \mathrm{~h}$ of treatment, the leaf Pi was estimated as $86.25 \pm 3.96 \mathrm{mg}$ for control and $62.70 \pm 5.36 \mathrm{mg} / 100 \mathrm{~g}$ of leaf for high temperature induced plant. High temperature caused a significant and more pronounced increase in Pi in leaf by $37.55 \%(P<0.01)$ (Fig. 4) when compared to the respective control. The increase of $\mathrm{Pi}$ in leaf was found to be higher than the previous $24 \mathrm{~h}$ of exposure as demonstrated in Fig. 1B, 2A, 2B. Therefore, the Pi content in leaf is assumed to be regulated by the variation of temperature and will be strictly followed by the extension of time.
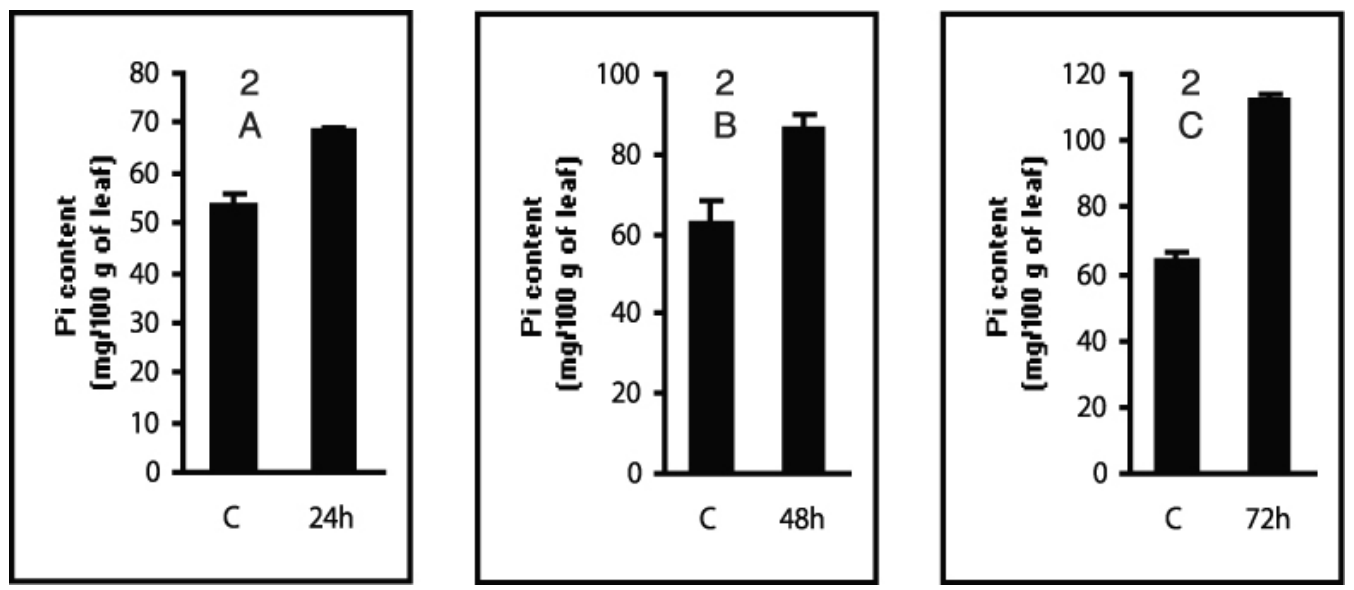

Fig. 2. High temperature induced regulation of $\mathrm{Pi}$ accumulation in leaves of Basella alba. Leaves of Basella alba were exposed to $45^{\circ} \mathrm{C}$ for $24 \mathrm{~h}(2 \mathrm{~A}), 48 \mathrm{~h}(2 \mathrm{~B})$ and $72 \mathrm{~h}(2 \mathrm{C}$ ) periods. The respective controls were kept in the room where the temperature remains $30^{\circ} \mathrm{C}$ and was maintained by air cooling system. After the treatments the leaves of the plants and their respective controls were used for determination of $\mathrm{Pi}$. The results are means of $\pm \mathrm{SE}$ for 3 values in each group.

Fig. $2 \mathrm{C}$ shows the effect of high temperature on Pi accumulation in leaf of plant after $72 \mathrm{~h}$ of exposure. Plants acclimated to high temperature had leaf Pi content of $112.31 \pm 1.92 \mathrm{mg}$ whereas $64.20 \pm 2.13 \mathrm{mg} / 100 \mathrm{~g}$ of leaf for control was observed. As the time extended, the amount of $\mathrm{Pi}$ in leaf had been enhanced in response to $45^{\circ} \mathrm{C}$. High temperature caused increased accumulation of Pi significantly $(P<0.001)$ by $74.93 \%$ compared to the control (Fig. 4), however, the effect was higher than the previous $24 \mathrm{~h}$ and $48 \mathrm{~h}$ exposure. The results suggested that the increased $\mathrm{Pi}$ in leaf might be due to the higher sensitivity of temperature and caused by temperature stress in the environment where they survived and could be considered as the survival factor as well as index for characterization of physiology of leaf of this species.

\section{Discussion}

In the present study, both low and high temperature has been found to be involved in the higher accumulation of inorganic phosphate in leaf of Basella alba, however the effects were more pronounced in high temperature induced leaf than that of low temperature. The mechanism of formation of inorganic phosphate in response to the temperature stress is not yet clearly known. However, several lines of evidences might be involved to clarify and recognize the formation of the molecule inorganic phosphate in such adverse situation. It has been shown that low temperature causes the higher oxidative stress inducing 
the synthesis of active oxygen species (AOS) (Lee and Lee 2000) and increases tolerance to AOS in cereals and with an increase in anti oxidative enzymes (Mahajan and Tuteja 2005, Kuk 2003). Anti oxidative enzymes can neutralize AOS (Lee and Lee 2000, Odaira et al. 2000) and thereby prevents the cellular membranes and organelles from the damaging effects of AOS (Foyer et al. 1991). Similarly, heat stress or high temperature is also involved in the synthesis of AOS (Mei and Song 2010). High temperature affects the metabolism and structure of plants, especially cell membranes and many basic physiological processes such as photosynthesis, respiration and water relations (Wahid et al. 2007). On the molecular level, this effect of heat stress reflects the temperature dependences of Michaelis-Menten constant (Km) of every enzyme participating in the process (Mitra and Batia 2008). Plants must cope with heat stress for survival, so they developed different mechanisms including the maintenance of cell membrane, stability, capturing the reactive oxygen species (ROS), synthesis of antioxidants, accumulation and osmoregulation of osmoticum, induction of some kinases that respond to stress. Therefore, the higher synthesis of Pi in the present study in response to both low and high temperature might be linked to the formation of ROS in plant organelles. As the plants survive in such adverse situations, they need the use of Pi as released from the substrate. During low or high temperature exposure, plants may have nutritional deficiency and the accumulated Pi may serve as the molecule giving phosphorus which is very essential element for plant nutrition. Moreover, the energy released for hydrolysis of the energy rich compounds like adenosine triphosphate (ATP) or guanosine triphosphate (GTP) might be utilized to drive the metabolic processes in such adverse environmental circumstances. Since $\mathrm{Na}^{+}-\mathrm{K}^{+}$ATP-ase activity has been demonstrated to be increased by cold exposure (Videla et al. 1975), therefore, the increased $\mathrm{Pi}$ in leaf in response to cold temperature after $24 \mathrm{~h}, 48 \mathrm{~h}$ and $72 \mathrm{~h}$ periods might be due to the higher activity of this enzyme and higher degradation of cellular energy rich compounds such as ATP. The released Pi may play the role for survival of the species during cold acclimation

It is reasonable that the fluctuation of temperature can cause stress to the normal physiological functions of plants, and hence, alteration of metabolic activities in leaf of the plant might be observed. Previous studies revealed that low temperature had been associated with pronounced modifications in the ultrastructure of leaf cells, disorganization of cellular compartments (Stefanowska et al. 2002, Stefanowska et al. 1999) and therefore, may induce the synthesis of new enzymes and proteins. The structural change, therefore, may cause the alteration of metabolic processes, for example, protein phosphorylation-dephosphorylation reactions. It has been demonstrated that activation of the protein phosphatases of the type $2 \mathrm{~A}$ is mediated by cold acclimation resulting enhancement of dephosphorylation process (Yaneva et al. 2002, Antonio et al. 1998). The increased accumulation of $\mathrm{Pi}$ in leaf of plant in response to low temperature, therefore, might be due to the higher phosphorylation-dephosphorylation process. The energy rich molecules such as ATP might be degraded or hydrolyzed to produce Pi giving the energy which may be used to serve the reactions, so that the plants survive in the circumstances. Similarly, heat treatment may cause phosphorylation, dephosphorylation or degradation of ATP and other energy rich compounds to produce Pi. Therefore, the concentration of Pi might be increased. Behind this phenomenon, obviously increased oxidative stress should be connected since accumulated Pi in leaf was appreciably higher than the low temperature induced accumulation. However, all these phenomena may assist so that the plants survive in the environment.

During low temperature acclimation, increase of phosphorus playing an important role in plant metabolism is expected since the energy requirement for the circumstances can be obtained from phosphorus containing compounds. Moreover, low temperature storage is used to prolong the shelf life of fruit and vegetables. Muñoz et al. (2001) found that storage of fruit at $6{ }^{\circ} \mathrm{C}$ was associated with an increase in the total amount of $\mathrm{Pi}$ and phosphorylated metabolites and the preferential accumulation of Pi in the cytoplasm in chilled tissues have been confirmed by their experiments. During illumination at low temperature, pea leaves accumulated 
high quantities of sucrose, glucose-6-phosphate, fructose-6-phosphate, mannose-6-phosphate and phosphoglycerate (PGA) whereas ATP/ADP-ratios decreased (Streb et al. 2003). Therefore, the availability of inorganic phosphate plays a significant role for acclimation to such adverse conditions. High temperature stress directly or indirectly affects plant photosynthetic functions by changing the structural organization and physico-chemical properties of thylakoid membranes (Lichtenthaler et al. 2005). The rate of photorespiration increases with increasing temperature which reduces net photosynthesis and probably the seed yield of the crop. Rapid and effective measures of plant treatment are necessary so that deterioration of crops due to high temperature can be countered successfully. The application of plant growth regulators is known to play an important role in plant response to stress (Chakrabarti and Mukherjee 2003). The increased accumulation of inorganic phosphate in leaf in response to high temperature may serve as the molecule during this critical phenomenon like reduced photosynthesis.

\section{Conclusion}

During low or high temperature acclimation, plants possess nutritional or energy deficiency as they survive in such critical circumstances. The increased or accumulated inorganic phosphate in leaf may serve as the molecule released from the degradation of energetic compounds and the energy released by this process might be used in this case. The accumulated phosphate might be due to the higher oxidative stress which causes the synthesis of reactive oxygen species (ROS). Therefore, assay of inorganic phosphate during the temperature stress might be a useful parameter to the physiological responses or could be an index for characterization of the physiological and metabolic status of Basella alba.

\section{Acknowledgement}

This study was carried out in the Department of Biochemistry and Molecular Biology, Rajshahi University and was supported by the University Grant Commission (UGC), Bangladesh.

\section{References}

Antonio FM., Veena S, Rajinder SD. 1998. Low temperature signal transduction during cold acclimation: Protein phosphatase 2A as an early target for cold-inactivation. The Plant Journal 13 (5), 653-660. http://dx.doi.org/10.1046/.1365-313X.1998.00070.x

Basra AS. 2001. Crop responses and adaptations to temperature stress, In: T.K. Prasad (ed.). Mechanisms of chilling injury and tolerance. Basra, Senior Editor, Haworth Press Inc. New York. 1- 34 pp.

Chakrabarti N, Mukherjee S. 2003. Effect of phytohormones pretreatment on nitrogen metabolism in Vigna radiata under salt stress. Biol Plant 36, 63-66. http://dx.doi.org/10.1023/A:1022358016487

Foyer CH, Lelandais M, Galap C, Kunert KJ. 1991. Effect of elevated cytosolic glutathione reductase activity on the cellular glutathione pool and photosynthesis in leaves under normal and stress conditions. Plant Physiol 97, 863872. http://dx.doi.org/10.1104/pp.97.3.863

Kuk YI. 2003. Relationships of cold acclimation and antioxidative enzymes with chilling tolerance in cucumber (Cucumis sativus L.). J Amer Soc Hort Sci 128(5), 661-666.

Lee DH, Lee CB. 2000. Chilling stress-induced changes of antioxidant enzymes in the leaves of cucumber: In gel enzyme activity assays. Plant Sci 159, 75-85. http://dx.doi.org/10.1016/S0168-9452\%2800\%2900326-5

Larcher W. 2003. Physiological plant ecology, 4th edn. Springer. http://dx.doi.org/10.1007/978-3-662-05214-3

Lichtenthaler HK, Langsdorf G, Lenk S, Buschamann C. 2005. Chlorophyll fluorescence imaging of photosynthetic activity with the flesh lamp fluorescence imaging system. Photosynthetica 43, 355-369. http://dx.doi.org/10.1007/s11099-005-0060-8 
Mahajan S, Tuteja N. 2005. Cold, salinity and drought stresses: An overview. Arch Biochem Biophys 444, 139-158. http://dx.doi.org/10.1016/.abb.2005.10.018

Mitra R, Bhatia CR. 2008. Bioenergetic cost of heat tolerance in wheat crop. Curr Sci 94, 1049-1053

Muñoz T, Ruiz-Cabello J, Molina-García AD, Escribano MI, Merodio C. 2001. Chilling temperature storage changes the inorganic phosphate pool distribution in Cherimoya (Annona cherimola) fruit. J Amer Soc Hort Sci 126(1), 122-127.

Mei $Y$, Song S. 2010. Response to temperature stress of reactive oxygen species scavenging enzymes in the crosstolerance of barley seed germination. J Zhejiang Univ-Sci B (Biomed \& Biotechnol) 11(12), 965-972.

Oidaira H, Satoshi S, Tomokazu K, Takashi U. 2000. Enhancement of antioxidant enzyme activities in chilled rice seedlings. Plant Physiol 156, 811-813. http://dx.doi.org/10.1016/S0176-1617\%2800\%2980254-0

Premalatha B, Rajgopal G. 2005. Cancer- an ayurvedic perspective. Pharmacol Res 51, 19-30. http://dx.doi.org/10.1016/.phrs.2004.04.010

Roshan A, Naveen KHN, Shruthi SD. 2012. A review on medicinal importance of Basella alba L. Int J Pharma Sci Drug Res 4(2), 110-114.

Ramnik S. 1999. Medical laboratory technology: Methods and interpretations. Jaypee Brothers, Medical publishers (P) Ltd., New Delhi. pp 485-487.

Stefanowska M, Kuras M, Kubacka-Zebalska M, Kacperska A. 1999. Low temperature affects of growth and structure of cell wall in winter oilseed rape (Brassica napus L. var. oleifera L.) plants. Annals of Botany 84, 313-319. http://dx.doi.org/10.1006/anbo.1999.0924

Stefanowska M, Kuras M, Kacperska A. 2002. Low temperature-induced modifications in cell ultrastructure and localization of phenolics in winter oilseed rape (Brassica napus L. var. oleifera L.) leaves. Annals of Botany 90, 637-645. http://dx.doi.org/10.1093/aob/mcf241

Streb P, Aubert S, Gout E, Bligny R. 2003. Cold- and light-induced changes of metabolite and antioxidant levels in two high mountain plant species Soldanella alpina and Ranunculus glacialis and a lowland species Pisum sativum. Physiologia Plantarum 118, 96-104. http://dx.doi.org/10.1034/.1399-3054.2003.00099.x

Videla L, Flattery KV, Sellers EA, Israel Y. 1975. Ethanol metabolism and liver oxidative capacity in cold acclimation. The Journal of Pharmacology and Experimental Therapeutics 192, 575-582.

Wahid A, Gelani S, Ashraf M, Foolad MR. 2007. Heat tolerance in plants: an overview. Environ Exp Bot 61, 199-223. http://dx.doi.org/10.1016/i.envexpbot.2007.05.011

Yaneva IA, Hoffmann GW, Tischner R. 2002. Nitrate reductase from winter wheat leaves is activated at low temperature via protein dephosphorylation. Physiol Plant 114(1), 65-72. http://dx.doi.org/10.1034/i.1399-3054.2002.1140110.x 